\section{Delayed hyperbaric oxygen treatment for acute carbon monoxide poisoning}

Hyperbaric oxygen is the preferred treatment in acute carbon monoxide poisoning. Though it should be started as soon as possible, we wish to emphasise that anyone who has been exposed to carbon monoxide should be treated regardless of the delay between exposure and presentation. ${ }^{1}$ We present our experience with delayed hyperbaric oxygen treatment for acute carbon monoxide poisoning.

\section{Patients and results}

From January 1982 to February 1983 we treated 10 cases of acute carbon monoxide poisoning. In six cases there was a delay of seven to 16 hours from the time of rescue to the beginning of treatment with hyperbaric oxygen. The duration of exposure to the environment rich in carbon monoxide varied from a few minutes (three patients caught in fires) to 14 hours. Four of the six inhaled smoke. The table gives clinical details on the six patients. They were at different levels of consciousness when rescued. Electrocardiography showed ischaemic changes in two cases, and all had metabolic acidosis. Five made full mental and physical recoveries. One (case 2 ) did not improve: he developed hydrocephalus with increased intracranial pressure and finally died.

\section{Comment}

Carboxyhaemoglobin concentrations correlate only roughly with clinical condition. Goldbaum et al explained this in their study of three groups of dogs. ${ }^{2}$ In the study one group of dogs was given $13 \%$ carbon monoxide by inhalation. All died with carboxyhaemoglobin concentrations of $54-90 \%$. A second group of dogs were bled until their haemoglobin concentration had been reduced by $68 \%$ : they were then reinfused with Ringer's solution and dextran and all survived. A third group of dogs were also bled until their haemoglobin concentration had been reduced by $68 \%$, but they then received transfusions of carboxyhaemoglobin red cells. These dogs had final carboxyhaemoglobin concentrations of $57-64 \%$ and all survived. These results are explained by the exclusion of oxygen from the cytochrome oxydase $a_{3}$ enzyme by carbon monoxide. Carbon monoxide can reach the blood cells only when it is dissolved in the blood, which happens when it is breathed (as shown in the first group of dogs). The third group of dogs had no dissolved carbon monoxide in their blood, and their cytochrome oxydase $a_{3}$ activity was normal.

The carboxyhaemoglobin concentration immediately after exposure can be calculated roughly from the interval between exposure to carbon monoxide and the time of blood sampling, taking into account the half life of carboxyhaemoglobin, ${ }^{3}$ which is 320 minutes in room air and 80 minutes when $100 \%$ oxygen is being breathed. A long delay between rescue and blood sampling results in a poor correlation between carboxyhaemoglobin concentration and clinical signs. We measured carboxyhaemoglobin concentrations in only two of our patients (cases 4 and 6), and these were $1 \%$ and $0.6 \%$ respectively. The late neurological sequelae of acute carbon monoxide poisoning are almost certainly due to oedema and damage to the blood-brain barrier caused by hypoxia. This damage can be shown by computed tomography and confirmed at necropsy. ${ }^{4}$ Hyperbaric oxygen reduces the incidence of these phenomena, which is another reason for using this form of treatment regardless of whether there has been considerable delay.
Finally, we wish to draw attention to cases 4,5 , and 6 , in which the patients suffered lengthy exposure to the toxic environment and treatment was considerably delayed. Although prolonged exposure to carbon monoxide is known to carry much greater risks than short exposure ${ }^{5}$ these three patients responded well to hyperbaric oxygen treatment and left the hospital free of complaints.

We thank Mr Richard Lincoln for his valuable help with the manuscript.

1 Myers RAM, Snyder SK, Linberg S, et al. Value of hyperbaric oxygen in suspected carbon monoxide poisoning. F $A M A$ 1981;246:2478-80.

2 Goldbaum RL, Ramirez RG, Karel BA. What is the mechanism of carbon monoxide toxicity? Aviat Space Environ Med 1975;46:1289-91.

3 Clark CJ, Campbell D, Reid WH. Blood carboxyhemoglobin and cyanide levels in fire survivors. Lancet $1981 ; \mathrm{i}: 1332-5$.

4 Sawada Y, Sakamoto T, Nishide K, et al. Correlation of pathological findings with computed tomographic findings after acute carbon monoxide poisoning. $N$ Engl

Kindwall EP. Carbon monoxide and cyanide poisoning. In: Davis JC, Hunt TK, 1977:177-90.

(Accepted 17 fuly 1984)

Israeli Naval Hyperbaric Institute, PO Box 8040, Haifa 31080, Israel AVISHAI ZISER, $M D$, assistant director

AVI SHUPAK, MD, physician

PINHAS HALPERN, $M D$, physician

DAVID GOZAL, MD, physician

YEHUDA MELAMED, MD, director

\section{BMX bike injuries: the latest epidemic}

BMX biking is a major new craze throughout the Western world as much as skateboarding was a decade ago. To date there have been only two published reports of BMX bike injuries, both from Australia. ${ }^{12}$ During one week in May 1984 our hospital admitted five children with serious injuries sustained after falling off their BMX bikes. None of these injuries were fatal but they included major trauma to the liver and spleen, a fractured skull, a partially avulsed ear, a serious soft tissue injury to the abdominal wall, and a fracture dislocation at the wrist. Subsequently we conducted a survey to measure the problem in Southampton and to see whether any safety routines are being followed.

\section{Methods and results}

During a five week period from 1 June to 7 July 1984 all patients with BMX bike injuries presenting to the hospital were registered on a protocol. Details of the patient, the mechanism of injury, and any safety equipment used were recorded. Twenty three boys were registered during this period. The mean age was 11.7 (range $2.5-15.5$ ) and most were over 10 . No girls were seen with BMX bike injuries. Ten different models of BMX bike were used by these 23 children and one bike was homemade. The injuries sustained were as follows: to the arms (12) and legs (five): contusions (six); fractures (three: distal radius, scaphoid, and metatarsal); lacerations (three); abrasions (three); and sprains (two); to the abdomen (one); and to the head and neck: lacerations of chin, face, and scalp (three) and broken teeth (two). (All lacerations needed suturing.) Only one patient was admitted to hospital; he had a subcapsular haematoma of his spleen diagnosed by ultrasound. Managed conservatively, he did not require transfusion or surgery.

Thirteen of the 23 boys had sustained their injury during what they termed

Details of six patients on admission

\begin{tabular}{|c|c|c|c|c|c|c|c|c|}
\hline \multirow[b]{2}{*}{$\begin{array}{l}\text { Case } \\
\text { No }\end{array}$} & \multirow[b]{2}{*}{$\underset{\text { (years) }}{\text { Age }}$} & \multirow[b]{2}{*}{$\begin{array}{l}\text { Duration of exposure } \\
\text { to carbon monoxide }\end{array}$} & \multirow[b]{2}{*}{$\begin{array}{l}\text { Interval between rescue } \\
\text { and start of treatment } \\
\text { (hours) }\end{array}$} & \multirow[b]{2}{*}{ Level of consciousness } & \multirow[b]{2}{*}{ Clinical signs } & \multicolumn{3}{|c|}{ Blood gas tensions } \\
\hline & & & & & & $\underset{(\mathrm{kPa})}{\text { Oxygen }}$ & $\begin{array}{c}\text { Carbon } \\
\text { dioxide } \\
(\mathrm{kPa})\end{array}$ & $\mathrm{pH}$ \\
\hline $\begin{array}{l}1 \\
2 \\
3 \\
4 \\
5 \\
6\end{array}$ & $\begin{array}{l}2 \frac{1}{2} \\
3 \\
5 \\
20 \\
44 \\
70\end{array}$ & $\begin{array}{l}\text { Few minutes } \\
\text { Few minutes } \\
\text { Few minutes } \\
8 \text { hours } \\
14 \text { hours } \\
\text { Overnight }\end{array}$ & $\begin{array}{r}8 \\
7 \\
7 \\
12 \\
12 \\
16\end{array}$ & $\begin{array}{l}\text { Stupor } \\
\text { Deep coma } \\
\text { Coma } \\
\text { Fully conscious } \\
\text { Deep coma } \\
\text { Stupor }\end{array}$ & $\begin{array}{l}\text { Rales in both lung fields } \\
\text { Convulsions } \\
\text { Pulmonary oedema } \\
\text { ST segment elevation in leads V1, V2 } \\
\text { ST segment depression in most leads }\end{array}$ & $\begin{array}{r}6 \cdot 9 \\
50 \cdot 1 \\
9 \cdot 2 \\
13 \cdot 0 \\
13 \cdot 2 \\
14 \cdot 9\end{array}$ & $\begin{array}{l}3 \cdot 1 \\
5 \cdot 1 \\
6 \cdot 1 \\
4 \cdot 3 \\
4 \cdot 0 \\
5 \cdot 2\end{array}$ & $\begin{array}{l}7 \cdot 32 \\
7 \cdot 37 \\
7 \cdot 29 \\
7 \cdot 35 \\
7 \cdot 20 \\
7 \cdot 39\end{array}$ \\
\hline
\end{tabular}

Conversion: SI to traditional units-Oxygen and carbon dioxide tensions: $1 \mathrm{kPa} \approx 7.5 \mathrm{~mm} \mathrm{Hg}$. 
"normal cycling." The other injuries followed various stunts, including cycling up ramps (three) or performing specific BMX tricks such as "aerials," "jumps," "American bunny hops," "endos," "wheelies," and so on. No biker had received any supervised training in BMX riding or the correct performance of stunts. Only one boy was known to be wearing any protective clothing (a helmet and elbow pads) and he was riding his bike on a recognised BMX track. No injuries occurred as a result of mechanical failure of a bicycle.

\section{Comment}

BMX biking has been made popular by television, and many children in the United Kingdom now possess these bikes. Nevertheless, our small survey suggests that few wear or possess the correct safety equipment. The handlebars of a BMX bike are free to rotate through $360^{\circ}$ so that when the front wheel hits an obstruction the rider may be projected forwards and upwards and this may lead to scrotal and perineal injuries. ${ }^{12}$ The most serious injury we have seen (trauma to the liver) was caused by the rider being thrown up and landing on the handlebars.

By chance, we saw no serious injuries during the course of our survey, but in the next two weeks three boys were admitted with facial lacerations for suture under general anaesthetic after BMX trauma and one child suffered a fractured tibia and ipsilateral displaced epiphyseal ankle fracture.

We believe that the epidemic of BMX bike injuries has been underreported. Both parents and children appear to be unaware of the potential dangers and are ignoring reasonable safety measures.

1 Sparnon T, Moretti K, Sach RP. BMX handlebar-a threat to manhood ? Med 3

2 Burke AM. A serious BMX bike injury. Med f Aust 1982;2:263.

(Accepted 21 August 1984)

Departments of Accident and Emergency Medicine, Paediatric, and Orthopaedic Surgery, Southampton General Hospital, Southampton SO9 $4 X Y$

$S M$ SOYSA, FRCS, senior registrar in accident and emergency medicine

$M$ L GROVER, FRCs, lecturer in orthopaedic surgery and honorary senior registrar

P J MCDONALD, MS, FRCS, paediatric surgical registrar

Correspondence to: $\mathrm{Mr}$ McDonald, University Surgical Unit, Southampton General Hospital, Tremona Road, Southampton SO9 4XY.

\section{Increased storage of iron and anaemia in rheumatoid arthritis: usefulness of desferrioxamine}

Hyposideraemic anaemia is a common symptom of rheumatoid arthritis $^{12}$ similar to iron deficiency anaemia, with normal or low iron binding capacity and increased stores of iron. Iron accumulates in the reticuloendothelial system as $\mathrm{Fe}^{+++}$bound to ferritin and is therefore not available for erythropoiesis. ${ }^{3}$

The aim of this study was to ascertain whether the hyposideraemia in patients with rheumatoid arthritis is related to increased stores of iron and whether the depletion of stored iron that results from treatment with desferrioxamine restores the iron available for erythropoiesis.
Patients, methods, and results

We studied 63 patients ( 56 women, seven men) aged 23-74 with classic rheumatoid arthritis. All were being treated with non-steroidal antiinflammatory drugs and gold salts. Twenty two were normosideraemic and 41 hyposideraemic; age distributions in the two groups were similar.

We tested 21 hyposideraemic and 20 normosideraemic patients with an intramuscular injection of desferrioxamine $1 \mathrm{~g}$. The erythrocyte count, mean corpuscular volume, haemoglobin and serum iron and ferritin concentrations, unsaturated iron binding capacity, and urinary iron excretion were assessed before and 24 hours and 14 days after the test. The erythrocyte count, mean corpuscular volume, and haemoglobin concentration were also measured after seven days. The table compares the results.

Before the test serum iron concentrations and unsaturated iron binding capacity were significantly lower $(p<0.01)$ in hyposideraemic patients Serum ferritin concentrations were above the normal range in eight $(38 \%)$ of hyposideraemic and four $(20 \%)$ normosideraemic patients, although the difference was not significant. Haemoglobin concentrations were significantly higher $(p<0.05)$ and the erythrocyte sedimentation rate significantly lower $(p<0.01)$ in normosideraemic than hyposideraemic patients.

In hyposideraemic patients serum ferritin concentrations had fallen significantly and serum iron concentrations and urinary iron excretion had risen significantly 24 hours after administration of the drug. Unsaturated iron binding capacity did not change appreciably, and haemoglobin concentration showed an increase only seven days after the desferrioxamine load in hyposideraemic patients, with no further change after 14 days. The total erythrocyte count remained unchanged, but the mean corpuscular volume increased significantly in hyposideraemic patients. The erythrocyte sedimentation rate did not decrease significantly in hyposideraemic or normosideraemic subjects after the desferrioxamine load. Urinary iron was increased in normosideraemic patients and significantly increased in hyposideraemic patients after the test.

\section{Comment}

Of our patients with rheumatoid arthritis, $65 \%$ (41/63) were hyposideraemic. The pattern of anaemia consisted of low haemoglobin and serum iron concentrations and unsaturated iron binding capacity and high serum ferritin concentrations. Erythrocyte sedimentation rates were significantly higher in patients who had anaemia. The rise in serum ferritin concentration in these patients suggests that the accumulation of iron in the reticuloendothelial system may play a part in determining the hyposideraemic anaemia. This finding does not necessarily reflect raised stores of iron in tissue as ferritin is an acute phase reactant related to the activity of rheumatoid arthritis. ${ }^{4}$ The increased urinary iron after a single dose of desferrioxamine, however, confirmed an increased storage of iron in normosideraemic and, particularly, hyposideraemic patients with rheumatoid arthritis. The desferrioxamine test showed that iron is released from its storage and haemoglobin and serum iron concentrations increase significantly.

These findings seem to confirm that an increased uptake and a decreased release of iron from the inflamed synovial membrane may contribute to the occurrence of anaemia in patients with rheumatoid arthritis and suggest that treatment with iron may increase its storage and make the inflammation worse. ${ }^{4}$ Iron deposits in synovial membrane may promote damage, probably through the production of oxygen free radicals and the release of lysosomal enzymes. ${ }^{5}$ Our preliminary data suggest the possible usefulness of desferrioxamine to treat rheumatoid arthritis by removing iron from synovial membrane, decreasing synovial inflammation, restoring stores in bone marrow, and lessening anaemia.

1 Owen ET, Lawson AAH. Nature of anaemia in rheumatoid arthritis. VI. Metabolism of endogenous iron. Ann Rheum Dis 1966;25:547-52.

Mean (SEM) haematological variables in hyposideraemic and normosideraemic patients with rheumatoid arthritis before and after testing with a desferrioxamine load and 14 days later

\begin{tabular}{|c|c|c|c|c|c|c|}
\hline & \multicolumn{3}{|c|}{ Hyposideraemic patients $(n=21)$} & \multicolumn{3}{|c|}{ Normosideraemic patients $(n=20)$} \\
\hline & Before load & After load & After 14 days & Before load & After load & After 14 days \\
\hline $\begin{array}{l}\text { Erythrocytes }\left(\times 10^{12} / 1\right) \\
\text { Mean corpuscular volume }(\mathrm{f}) \\
\text { Haemoglobin }(\mathrm{g} / \mathrm{dl}) \\
\text { Serum iron }(\mu \mathrm{mol} / \mathrm{l}) \\
\text { Serum ferritin }(\mu \mathrm{g} / \mathrm{l}) \\
\text { Unsaturated iron binding capacity }(\mu \mathrm{mol} / \mathrm{l}) \\
\text { Urinary iron }(\mu \mathrm{g} / 24 \mathrm{~h}) \\
\text { Range } \\
\text { Erythrocyte sedimentation rate ( } \mathrm{mm} \text { in } 1 \mathrm{st} \mathrm{h})\end{array}$ & $\begin{array}{c}3 \cdot 6(0 \cdot 8) \\
71(6) \\
10 \cdot 9(1 \cdot 2) \\
6 \cdot 12(0 \cdot 34) \\
1 \cdot 84(0 \cdot 32) \\
48 \cdot 9(2 \cdot 6) \\
29 \cdot 7 \\
10-160 \\
60(23)\end{array}$ & $\begin{array}{l}3 \cdot 7(0 \cdot 5) \\
79(8) \dagger \\
12 \cdot 9(1 \cdot 18) \dagger \\
10 \cdot 54(0 \cdot 87)^{* * *} \\
0 \cdot 96(0 \cdot 17)^{* * *} \\
51 \cdot 8(2 \cdot 7) \\
596 \cdot 8 * * \\
60-1224 \\
55(12)\end{array}$ & $\begin{array}{l}3 \cdot 8(0 \cdot 4) \\
81(11)^{*} \\
12 \cdot 7(1 \cdot 5)^{*} \\
10 \cdot 92(1 \cdot 06)^{* * *} \\
0 \cdot 88(0 \cdot 15)^{* * *} \\
50 \cdot 3(3 \cdot 7) \\
\\
\quad 56(11)\end{array}$ & $\begin{array}{c}4 \cdot 3(1 \cdot 1) \\
85(5) \\
12 \cdot 2(1 \cdot 5) \\
13 \cdot 96(2 \cdot 15) \\
0 \cdot 94(0 \cdot 99) \\
50 \cdot 7(2 \cdot 9) \\
41 \\
10-160 \\
32(20)\end{array}$ & $\begin{array}{c}4 \cdot 6(0 \cdot 9) \\
84(9) \dagger \\
12 \cdot 5(2) \dagger \\
14 \cdot 66(2 \cdot 51) \\
0 \cdot 90(0 \cdot 86) \\
51 \cdot 9(2 \cdot 3) \\
302 \cdot 5 * * \\
60-520 \\
30(14 \cdot 2)\end{array}$ & $\begin{array}{l}4 \cdot 8(1 \cdot 2) \\
85(7) \\
12 \cdot 7(1 \cdot 9) \\
14 \cdot 14(1 \cdot 86) \\
0 \cdot 83(0 \cdot 74) \\
52 \cdot 8(4 \cdot 7) \\
\\
27(13 \cdot 5)\end{array}$ \\
\hline
\end{tabular}

$* \mathrm{p}=0.05, * * \mathrm{p}=0.02, * * * \mathrm{p}=0.01$. All other values not significant.

+Values obtained after seven days.

Conversion: SI to traditional units-Iron and unsaturated iron binding capacity: $1 \mu \mathrm{mol} / 1 \approx 0 \cdot 18 \mu \mathrm{g} / 100 \mathrm{ml}$. 